\title{
CORRESPONDENCE
}

their deep structures, are universal (i.e. at the deepest neuropsychic level, there exists a universal or 'archetypal' grammar on which all individual grammars are based); behavioural biologists conceive of innate releasing mechanisms responsible for species, specific patterns of behaviour; and ethologically oriented psychiatrists have begun to study what they call psychobiological response patterns which they hold responsible for the achievement of healthy or unhealthy patterns of adjustment in individual patients in response to variations in their social environment. All these concepts are compatible with the archetypal hypothesis which Jung proposed in the first decade of this century.

The question remains, however, whether Jung deliberately falsified his data. Though Noll is apparently convinced that he did, the evidence he produces is not sufficient to support his conviction. As Noll himself admits, Jung did attribute the case to Honneger in his first published account of it in 1911 (in Wandlungen und Symbole der Libido, Part I). Twenty years later, it is true, Jung claims the case as his own in his essay Die Struktur der Seele in 1930. This is not such a base slip as Noll would imply since Jung was the consultant under whom Honneger worked and therefore the man was technically Jung's patient. Though it is not possible after all this time to form a clear opinion of what occurred, the probability is that the truth is less sinister than Noll would wish to imply. It is undeniable that all his life Jung retained a fondness for the Solar Phallic Man. The case had provided a Eureka experience which strengthened his intuition that beneath our personal intelligence a deeper intelligence is at work - the evolved intelligence of humanity. That Jung may have exaggerated the unlikelihood of Honneger's patient knowing about the Mithraic cult, which specifically celebrated the phallic sun, probably represents nothing more venal than a natural human tendency to improve on a good story. But Jung's theory of archetypes operating through the collective unconscious is in no way dependent upon its veracity.

ANTHONY STEVENS

Fardel Manor, Near Ivybridge, Devon PL21 9HT

\section{Sulpiride and tardive dyskinesia}

Sir: We report on the development of tardive dyskinesia in a 37-year-old lady suffering from paranoid schizophrenia. Her illness was diagnosed in May 1989 and she was commenced on sulpiride $600 \mathrm{mg}$ bid. She remained on sulpiride continuously for the next four years except for a 5 -week period of non-compliance in 1989. The doses ranged from $100 \mathrm{mg}$ daily to $1200 \mathrm{mg}$ daily with an average of $600 \mathrm{mg}$. In January 1993 she was noted to have developed tardive dyskinesia.

The only other significant medication was chlorpromazine: the first course was prescribed in June ' 89 for 21 days, the second during Sept/ Oct ' 90 for 22 days and the third between Dec' 91 and March '92 for 94 days. The average daily dose of the first and third courses was $200 \mathrm{mg}$ daily, and that of the second course $400 \mathrm{mg}$ daily.

Although the exact aetiology of tardive dyskinesia is unknown, newer drugs with more specificity for selective dopamine receptor subtypes are thought to be associated with a lower incidence of extrapyramidal side effects. In this respect sulpiride is only $2-3$ times more potent at D2 than at D3 receptors in comparison with older antipsychotics which may have 10-20 times more affinity for the D2 versus the D3 receptor. However, reports have suggested a causal relationship between tardive dyskinesia and sulpiride (Herraiz, 1991; Miller, 1990). Although this patient was intermittently treated with chlorpromazine, the long-term use of sulpiride and the subsequent development of tardive dyskinesia supports a causal relationship between the two.

Herraiz, J., CANo, A. \& Rogue, J. (1991) Tardive dyskdnesta due to sulpiride. Medicina Clinica (Barcelona), 97, 235236.

MULER, L. G. \& JANKovic, J. (1990) Sulpiride-induced tardive dyskinesia. Movement Disorders, 6, 83-84.

BERNADETTE CULLEN

IAN DALY

St. Loman's Hospital,

Dublin

\section{MRCPsych examinations}

Sir: The MRCPsych examinations, Part $1 \& 2$, are very stressful for candidates and examiners, and bound to remain so (Mindham, 1995)! Concern about the patient management problems stems from the different views of trainers/consultants. Some believe a candidate is allowed to ask a question to be repeated but that writing it down is a bad sign while others encourage a candidate to write a question down if of help.

In the last examination, an examiner in my centre had his vignettes word-processed in very large letters and handed them to candidates while they answered the problems. This examiner prepared well for the examination (not at the last minute!). Top marks' went to him, not only from candidates examined by him, but from others who heard about it nationwide! I encourage other examiners to do likewise.

It may also help if all trainers/consultants have regular group updates, apart from information sent to them from the College, to discuss the examinations and ways to help their juniors. This 
will prevent situations where trainers ask Part 1 candidates what essays they wrote in the examination!

MindHAM, R. H. S. (1995) Arrangements for MRCPsych examinations. Psychiatric Bulletin, 19, 448-449

L. A. MARCUS

Gateshead NE8 1RD

\section{HoNOS, CPA CPGs \& Co}

Sir: I attended the meeting of the Royal College of Psychiatrists in Torquay and took part in one afternoon session looking at Health of the Nation Outcome Scales (HoNOS), Clinical Practice Guidelines (CPGs), and the Care Programme Approach (CPA).

Individually, each of these developments is difficult to fault, as will no doubt be those that follow. HoNOS perhaps has the potential for national audit and the examination of the effectiveness of treatment, CPGs may allow the standardisation of treatments/procedures which are generally felt to be the most beneficial, and the CPA presumably has the advantage of ensuring people are not forgotten or ignored. In spite of this I have reservations on all three.

The subjective element of HoNOS is open to considerable abuse if used nationally to sort out the best from the worst services (it is surely inevitable it will be used for this purpose). CPGs invite the unrealistic expectation of 'perfect' treatment at all times with the likelihood of legal repercussions in some cases. It would also seem likely a few patients will miss out on the benefit of a treatment that is felt by their doctor to be right but which isn't prescribed because it doesn't follow the particular CPG.

During the presentation on the CPA it was explained how a psychiatrist, assessing a person in an out-patient clinic, making a referral to a specialist counsellor, following up the patient at a subsequent clinic, and calling themselves the keyworker, could then document that they had followed the CPA for this particular individual and by implication be satisfied with their thorough approach. Since this would have been normal practice in any case, the exercise in this case seems pointless while creating additional paperwork.

Individually, none of these approaches is bad; however, each is something more to remember or consider, and I can't help wondering if they will be the last 'innovations'. They also seem to require the unrealistic expectation that doctors will be perfect at all times, i.e. perform at the standard of the best available (a similar argument might suppose we should all be able to run 100 metres in 10 seconds, since this is the standard for optimum human achievement).

Perhaps the worst aspect is that in applying HoNOS, recalling all relevant CPGs, and successfully documenting CPAs, along with audit activity, business information and the rest that is currently demanded, there may be insufficient time to look at the clinical picture presented to us and consider properly how best to offer help.

M. J. DICKINSON

St. Ann's Hospital

London N15 3TH

\section{Schizophrenics, the unnameable?}

Sir: Two fundamental problems in finding an acceptable way of describing 'an individual with schizophrenia' are the status of schizophrenia as an illness and the context in which the description is used. Haghighat \& Littlewood (Psychiatric Bulletin, July 1995, 19, 407-410) offer a valuable analysis of language, but are writing expressly in the medical model. The proviso, "if... people avoid certain linguistic forms... even when they accept that they have developed the corresponding illness..." avoids the issue. Whether one accepts the arguments against schizophrenia as a discrete entity or not, the 'safest' (least stigmatising? Most acceptable?) description may be, 'an individual with the diagnosis of schizophrenia'. This both allows for the medical model but begs the question of the existence of schizophrenia. The use of the word 'sufferer' is not without problems, not least the theological imperatives implied in the word (Atkinson, 1993), and that it seems to suggest the person's whole life is one of suffering.

Current labels/descriptions used by 'patients' focus on behaviour/experience, such as voice hearer' favoured by those in the Hearing Voices Network, or 'status', such as 'survivors' (of the system or of the illness) as in the group Survivors Speak Out. 'User' is common and often used as the best of a bad lot. In her last editorial (1995) in Openmind, Helen Imam confesses "that I never did like the term 'user' (nor 'carer' come to think of it!)" and the incoming editor offers a prize for "the best argued case for a better word than'user'" (Daley, 1995). 'User' can be seen to imply choice, which many 'users' would deny they had.

Different situations call for different degrees of precision. 'People with mental health problems' fits some situations, but some argue that it diminishes the seriousness of their problem. The problems and stigma surrounding descriptive/diagnostic terms are not special to psychiatry. The disability rights movement eschews medical labels, seeing these as a major hindrance to overcoming barriers to their integration into society. 